\title{
An assessment by nurses and mothers of a 'road-to-health' book in the Western Cape
}

\section{Harrison, SRN}

Division of Paediatrics and Child Health, School of Child and Adolescent Health, University of Cape Town

H Harker, SRN

Division of Paediatrics and Child Health, School of Child and Adolescent Health, University of Cape Town

\section{HdeV Heese, MD, BSc, FRCP Edin, DCH}

Division of Paediatrics and Child Health, School of Child and Adolescent Health, University of Cape Town

\section{Mann, PhD, MMed(Paed), MMed(Nuc Med)}

Division of Paediatrics and Child Health, School of Child and Adolescent Health, University of Cape Town

Keywords:

Records, road-to-health card, growth chart

\section{Abstract: Curationis 28(4): 57-64}

Objectives: To evaluate English, Afrikaans, and Xhosa mother-retained 'Road-toHealth Book' (RTH book) for children, and an electronic calculator.

Design: Researchers D Harrison (DH) and H Harker $(\mathrm{HH})$ informed clinic staff about the contents and significance of the RTH book. They requested nurses to use this book in conjunction with the Road-to-Health Card and to issue and explain its use to every visiting client. The use of an electronic calculator that plotted horizontal centile and Z-score charts was demonstrated and explained. To determine the relevance of the book and the electronic calculator, nurses involved in the study for 6 months were given three standardised descriptive questionnaires with 'yes', 'no' and 'don't know' responses. Clients were traced and interviewed by the researchers after $6-12$ months to obtain their views on the book.

Setting: Clinics that provided children with healthcare in 24 locations in the Western Cape Province participated in the study. The children lived in informal settlements, in low-, middle- and high-income residential areas, and on farms in the Cape Town. Stellenbosch, and Paarl regions.

Subjects: One hundred and fourteen nurses were enrolled in the study as well as 581 clients to whom the RTH book was issued.

Outcome measures: The use of and comments on the RTH book by nurses and clients were based on analysis of the questionnaires.

Results: The majority of nurses ( $81.6 \%$ ) and clients (96\%) found the RTH book useful. The horizontal and Z-score growth charts and electronic calculator were less acceptable because their use was time-consuming and less well understood.

Conclusion: The RTH book with appropriate modifications should be issued to clients in place of the current Road-to-Health card and educational material.

\section{Correspondence address:}

Denise Harrison

Division of Paediatrics and Child Health

Red Cross Children's Hospital

Klipfontein Road

Rondebosch 7700

E-mail: 


\section{Opsomming}

Doelstellinge: $\mathrm{Om}$ die "Pad-NaGesondheid Boek" (PNG boek) beskikbaar in Engels, Afrikaans en Xhosa, wat in die moeder se besit bly, en ' $n$ elektroniese rekenaar te evalueer.

Ontwerp: Navorsers D Harrison (DH) en $\mathrm{H}$ Harker $(\mathrm{HH})$ het die personeel van klinieke ingelig oor die inhoud en betekenis van die PNG boek. Die verpleegsters is versoek om die boek tesame met die Pad-Na-Gesondheid kaart (PNG kaart) te gebruik, die boek uit te reik aan elke besoekende klient en die gebruik daarvan te verduidelik. Die gebruik van 'n elektroniese rekenaar met spesiale funksies benodig vir die kartering van horisontale en Z-tellinggroeikaarte is gedemonstreer en verduidelik. Na 6 maande is aan die verpleegsters van die klinieke betrokke by die studie, 3 eenvormige beskrywende vraelyste met 'ja', 'nee' of 'weet nie' antwoorde gegee om hulle menings oor en evaluering van die PNG boek en elektroniese rekenaar te verkry. Kliente is 6-12 maande later deur $\mathrm{DH}$ en $\mathrm{HH}$ opgespoor vir onderhoude om hulle siening oor die boeke te bekom.

Studieveld: Vier-en-twintig (24) klinieke wat kinders met gesondheidsorg bedien in die Westelike Provinsie. Die kinders het in informele nedersettings, lae-, middel- en- hoë-inkomste woongebiede, en op plase in die distrikte van Kaapstad, Stellenbosch en Paarl gewoon.

Deelnemende persone: Een honderd en veertien (114) verpleegsters en 581 kliente het die PNG boek ontvang.

Resultaat material: Vraelyste betreffende die gebruik van die boek deur die verpleegsters en klients is ontleed.

Resultate: Die meederheid van die verpleegsters $(81.6 \%)$, en van die kliente (96\%) het die PNG boek nuttig gevind. Die horisontale- en Z-tellinggroeikaarte en elektroniese rekenaar was minder aanvaarbaar, aangesien gebruik daarvan tydrowend gevind is en dit moeilik was om te verstaan.

Gevolgtrekking: Die PNG boek met toepaslike veranderinge behoort aan kliente gegee te word in plaas van die PNG kaart en opvoedkundige lektuur wat tans gebruik word.

\section{Introduction}

In many countries, patient-retained books (PRBs) rather than cards are favoured for the personal health records of preschool children. The former motivate mothers and caregivers (clients) to become more active in managing the health of their children (Saffin \& Macfarlane, 1991,pp.249-251). Clients are encouraged to enter details themselves so that a complete health document may be compiled. These home-based documents vary in complexity but most have pages for immunisations, developmental milestones, and anthropometric measurements (including single-sex weight charts), illnesses and health information such as accident prevention. Advantages and difficulties in the use of such a book in the UK are concisely given by Macfarlane, 1992, pp. 571-572. Patient-retained records were introduced at the Alexandra Clinic in Johannesburg in 1992 (Daviaud, Cebekhulu \& Moniez, 1996, pp.986-987) and are still in use (personal communication Prof. David Power, 2004). PRBs, after evaluation, are in wide use and accepted in many countries by health authorities, health staff, and clients for monitoring children's health. There is a paucity of references in recent years on the subject. The authors therefore decided to evaluate a PRB in a paediatric group.

Research by the authors supported the introduction of a retained record of the health of a child by a client in the Western Cape (Harrison, Heese, Harker \& Mann, 1998, pp. 1425-1426). Recommendations made by a spectrum of clinic staff and clients interviewed by the researchers $\mathrm{D}$ Harrison $(\mathrm{DH})$ and $\mathrm{H}$ Harker $(\mathrm{HH})$ were incorporated in a draft RTH book, printed in English. This book differed from the 'Personal child health book' in the UK in that its final contents were largely determined by clinic staff and clients of the Western Cape. The UK book was compiled by representatives of various associations interested in child health (British Paediatric Association, 1990).

In the Western Cape clinic staff and clients had little or no in-put in the Roadto-Health card currently in use in the area. Medical personnel and senior Public Health nurses interested in child health in the Western Cape determined the Road-to-Health card's format, contents and use in clinics in the Western Cape. Modifications and improvements by provincial health departments and the Department of Health from 1973 resulted in its eventual general introduction in South Africa. Two of the authors, $\mathrm{DH}$ and $\mathrm{HH}$, assessed the use of a draft RTH book in child health clinics in Cape Town in conjunction with clinic staff and clients. Their findings showed that the RTH book with additions and changes could improve existing record-keeping, health education, and health monitoring. These observations supported previous research that the Road-to-Health card has too many deficiencies to be an effective education document and is viewed unfavourably by health personnel and clients (Harrison, et al, 1998).

Nursing and medical personnel responsible for the delivery of child health services at clinics and crèches in Cape Town and its environs were invited by the authors to review the response of clinic staff and clients to their experience of and comments on the draft RTH book. They were requested by the authors to make alterations and additions to be incorporated in a new version of the RTH book. The latter was printed in English, Afrikaans and Xhosa, and the titles were respectively 'My Road-to-Health Book', 'My Pad-na-Gesondheid Boek', and 'Incwadi Yam Yendlele Eya Empilweni'.

The current paper evaluates the attitudes of 114 nurses and 453 clients to the RTH book. Twenty-one of the clients were not the mother of the child. This number is small and in the remainder of the text and tables the word 'clients' includes caregivers. Nurses and clients were from a broad spectrum of the Cape Peninsula population who worked in or attended rural and metropolitan child health clinics. They had not participated in the evaluation of the draft RTH book or the Road-to-Health card study (Harrison, et al, 1998).

The Medical Ethics Committee of the Faculty of Medicine of the University of Cape Town approved the study protocol.

\section{Tools}

\section{Book}

The RTH book was a compact 58-page document in a sturdy laminated plastic cover produced for R4 in 1996 (for an order of 600 books). It measured $10 \mathrm{~cm}$. by $15 \mathrm{~cm}$. and fitted easily into a pocket or handbag.

The size and contents had been determined by clinic staff and clients in the pilot study of the draft RTH book (unpublished). The format and contents reflected the perceived needs of clinic staff and clients to enable them to monitor 
Table I : Distribution of the number of RTH books by age and location.

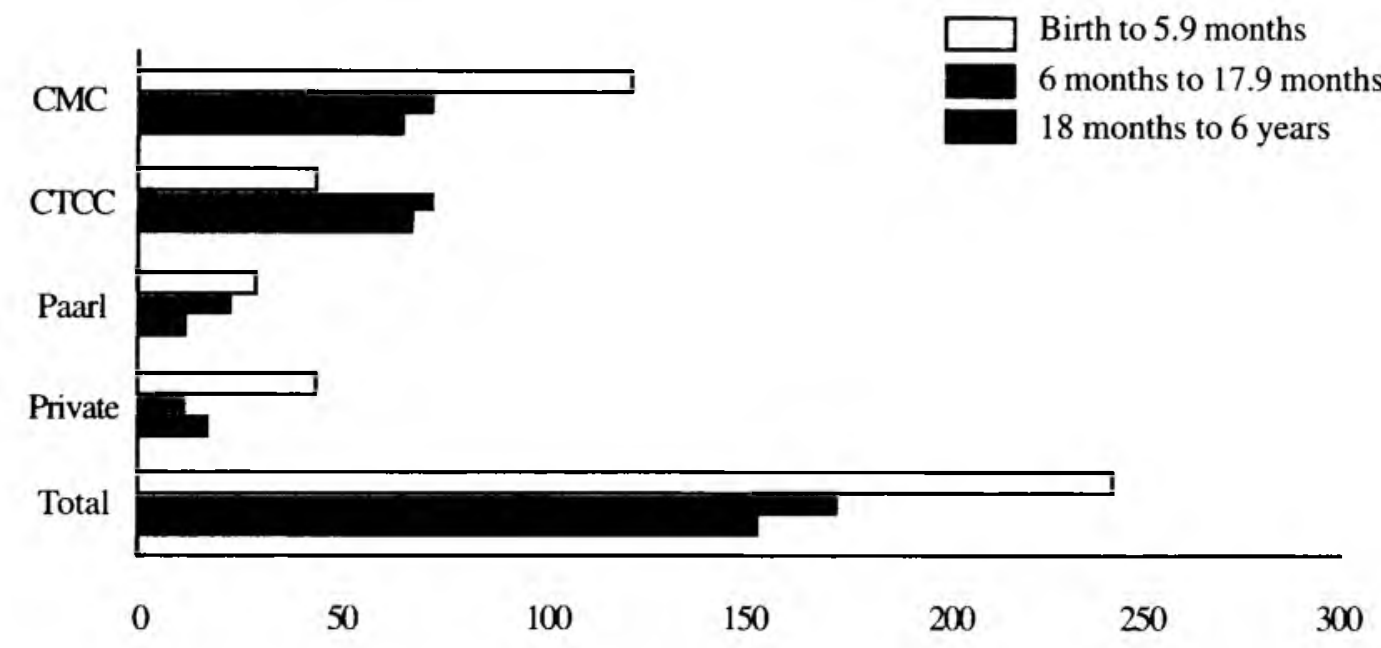

CMC - Cape Metropolitan Council including rural Stellenbosch \& Paarl

CTCC - Cape Town City Council

Paarl Municipality

the health of infants at clinic and maternal level. Further additions and modifications were made to the draft RTH book at a meeting with the authors and senior nursing and medical personnel responsible for child health services in the then Cape Town Metropolitan area. These were incorporated in the RTH book reported on in this study. The book included all specific information which should be entered on the Road-to Health card.

The first page contained the infant's name, identity number, sex, and date of birth as well as the names of mother, father, and/or caregiver. The next page was devoted to the current address and spaces for changes of address. Prenatal and postnatal details on page 3 were similar to those in the Road-to-Health card. The next pages were for additional information such as allergies, operations, chronic illnesses, de-worming, admissions to hospital, and hearing and vision tests. The detailed immunisation schedule required double pages. Each immunisation such as polio or BCG was printed opposite its relevant age group and the method of administration was listed. There was also information for clinic staff on illnesses and conditions which do not preclude immunisation such as minor illnesses with a fever of less than $38.5^{\circ} \mathrm{C}$, diarrhoea and respiratory infections. Notes on possible adverse reactions after immunisation, such as pyrexia, were given and clients were advised what to do in these circumstances. A table for recording infectious diseases was included. The pilot study showed that clients did not remember dates of previous illnesses and hospitalisations, so a place was included for these to be noted.

A unisex growth chart in the RTH book was similar to the one used in the Roadto-Health card and a horizontal centile chart was also included. These charts were divided into 3 groups to facilitate plotting, for each of the following ages: birth to 6 months, 6 to 18 months, 18 months to 6 years. One double page was allocated to each of the three age groups. Each double page had a chart with demarcations and a note page. The charts were backed up by an intervention chart on which accurate standard deviations of weight (Z-scores) calculated by the electronic calculator could be plotted for those whose growth fell outside the normal range, and in particular below the third centile line on the unisex charts. The RTH book's horizontal Z-score chart bears a closer resemblance to a chart devised by Sorva, Perheentupa \& Tolpannen, 1984, pp. 527529 than the one in the World Health Organisation version of the Road-toHealth chart in Lesotho (Ruel, Pelletier, Habicht, Mason, Chobokoane \& Maruping, 1991, p.612).

An illustrated developmental chart displayed milestones where separate columns were provided for clients and staff to record their observations. Eight blank pages were provided for staff and clients to make general notes.

The next pages of the book contained advice on common minor and major health problems which a client might well encounter. Included was advice on breast and bottle-feeding, types of stools, recommended sleeping positions such as back and side, and recommended diets for weaning and for children up to 6 years. Minor ailments such as rashes, sticky eyes, blocked nose, oral thrush, worms, and cradle cap were also included. The notes on major ailments outlined the care of babies and children with burns, tuberculosis, AIDS, coughs or difficult breathing and those with diarrhoea and vomiting. An illustrated recipe for oral rehydration therapy and indications for seeking further medical help appeared in the notes. Warning signs included the baby who has more than 5 watery stools in one day, is vomiting, passes little urine, has a dry mouth and tongue, has slightly sunken eyes, is listless and has lost weight.

The book concluded with the symptoms and incubation periods of common infectious diseases and listed the phone numbers of support groups as well as the details of clinic attendances and appointments. An index on the inside of the front cover was included for easy reference.

\section{Calculator}

The researchers issued each clinic with one or more battery-operated hand-held 
Table Il: Information extracted from 453 RTH books completed by nurses, clients and researchers.

\begin{tabular}{|lllllr|}
\hline Information & $\begin{array}{l}\text { Number } \\
\text { of books }\end{array}$ & \% completed & Items & Number & \% completed \\
of books & \\
Date of birth & 452 & $99.8 \%$ & Apgar 1 & 379 & $83.7 \%$ \\
Sex & 449 & $99.1 \%$ & Apgar 5 & 369 & $81.5 \%$ \\
Surname & 452 & $99.8 \%$ & Birth complications & 453 & $100.0 \%$ \\
Child & 452 & $99.8 \%$ & Discharge date & 321 & $70.9 \%$ \\
Mother & 444 & $98.0 \%$ & Discharge weight & 241 & $53.2 \%$ \\
Father & 302 & $66.7 \%$ & Discharge feed & 409 & $90.3 \%$ \\
Caregiver & 256 & $56.5 \%$ & Gravida & 380 & $83.9 \%$ \\
Identity number & 126 & $27.8 \%$ & Para & 377 & $83.2 \%$ \\
Address & 431 & $95.1 \%$ & Pregnancy complications & 379 & $83.7 \%$ \\
Telephone number & 199 & $43.9 \%$ & Labour complications & 384 & $84.8 \%$ \\
Place of birth & 421 & $93.1 \%$ & Delivery complications & 393 & $86.8 \%$ \\
Birth weight & 426 & $94.0 \%$ & Family planning & 300 & $66.2 \%$ \\
Circumference of head at birth & 390 & $86.1 \%$ & Clinic named & 423 & $93.4 \%$ \\
Length at birth & 247 & $54.5 \%$ & Clinic telephone number & 215 & $47.5 \%$ \\
Gestational age & 311 & $68.7 \%$ & Clinic times & 199 & $43.9 \%$ \\
& & & Folder number & 94 & $20.8 \%$ \\
\hline
\end{tabular}

electronic calculators developed specifically for this study by an electronics engineer and one of the authors. The calculator displayed an accurate age, weight-for-age and standard deviation for weight (needed to plot weight on the horizontal and Z-score charts in the RTH book). Nurses used the electronic calculator for other purposes, such as determining the fluid requirements for various ages, and weekly statistical information required for administrative purposes. A researcher instructed nurses of each clinic or crèche how to use the calculator until they were familiar with its use and functions.

\section{Questionnaires}

Three standardised descriptive questionnaires were given to the nurses. Anonymity was assured as no names appeared on the questionnaires and answers were 'yes', 'no' or 'don't know'. Questionnaire 1 determined the relevance and usefulness of the content of the book and whether it fulfilled the identified need to improve record keeping, health education and health monitoring. Questionnaire 2 investigated the acceptance by and understanding of nurses of the growth charts.

Each nurse also received a birth-to-six month weight-for-age chart and a horizontal centile chart, which contained entered weights of four infants. One of the infants had grown normally, another had extended above the $97^{\text {th }}$ centile, the third had fallen below the $3^{\text {rd }}$ centile and then started to regain weight, and the fourth had remained below the third centile. Nurses were requested to select the charts showing a normal growth pattern, an overweight child and one with malnutrition. Questionnaire 3 evaluated the role and efficiency of the electronic calculator.

Questionnaire 4 was completed by clients and focused on three aspects: the usefulness of the book, the value of the education sections and the clarity of the various growth charts. The same growth patterns that staff had been presented with on the birth-to-six-month weight-forage and horizontal centile charts were shown to each client to identify as normal, overweight or malnourished growth patterns.

The pilot study had indicated that there were certain needs to be met and the questionnaires were designed for a larger group of nurses and clients to confirm that these original recommendations were correct. In questionnaires 1 and 4 , nurses and clients were asked to give a reason for their responses. These comments assisted the authors in compiling their recommendations.

\section{Method}

The two researchers visited each clinic twice a month and stayed until nurses had attended to all the clients at the clinic. One (DH) was fluent in Afrikaans, English and Xhosa and the other $(\mathrm{HH})$ in Afrikaans and English. They orientated the nurses regarding the contents and significance of the RTH book and encouraged them to make notes in the book. They helped to distribute 46 percent of the books issued to clients, especially in those clinics where nurses had to deal with large numbers of clients and children.

A nurse or a researcher explained each page of the RTH book to a client and requested that she produce it at visits to hospitals, clinics, and doctors. Clients were encouraged to make their own notes in the relevant sections and to ensure that health personnel fully recorded their findings and advised management. The study of the Road-to-Health card (Harrison, et al, 1998) frequently found that certain sections of a child's card were inadequately completed by health personnel in the public and private sector.

A green sticker on the Road-to-Health card of a child identified participation in the study and reminded staff to complete the RTH book. After 12 months, 466 (80\%) of the 581 clients who had received a book could be traced and consented to be interviewed. The two researchers 


\begin{tabular}{|lll|}
\hline Information & Number of books & Percentage completed \\
Immunisation for Polio complete & 419 & $92.5 \%$ \\
Immunisation for BCG complete & 404 & $89.2 \%$ \\
Immunisation for DPT complete & 414 & $91.4 \%$ \\
Immunisation for Heppacine complete & 277 & $61.1 \%$ \\
Immunisation for Measles complete & 317 & $70.0 \%$ \\
All items plotted on charts & 310 & $76.9 \%$ \\
Notes from staff & 293 & $64.7 \%$ \\
Notes from doctor & 54 & $11.9 \%$ \\
Notes from other & 23 & $5.1 \%$ \\
Notes from mother & 165 & $36.4 \%$ \\
\hline
\end{tabular}

conducted interviews with four hundred and fifty-three (453) clients with books. Thirteen $(2.8 \%)$ of the 466 clients were not able to produce their books because they had been lost.

A researcher interviewed each client in her own language at a time and place (home, workplace, or clinic) that suited her. The interview lasted for approximately 30 minutes. The use of each page of the book was extracted and the book was returned to the client.

The baby's name and data such as date and place of birth were often completed immediately after the books had been given to the clients. The researchers may have possibly influenced clients and nurses. Completion of immunisation records, weights, and developmental assessments, and other sections of the book, however, took place at subsequent visits when the researchers were not present and so were unlikely to have had a direct influence.

\section{Setting \\ Clinics}

The investigators wished to survey as wide a range as possible of the clinic nurses and clients in the Cape Town, Stellenbosch and Paarl regions of the Western Cape. Advice and permission were sought from The Health Departments of the Cape Town City Council and Cape Regional Services Council regarding clinics we wished to approach. Researchers $\mathrm{DH}$ and $\mathrm{HH}$ visited the nurses of the suggested clinics and crèches to explain all aspects of the proposed study and invited them to participate in the study on a voluntary basis. The response was enthusiastic and none declined. The Clinics which accepted were distributed as follows: Cape Town City Council ( 5 clinics and 2 crèches), Western Cape Regional Services Council ( 9 clinics including 2 mobile clinics covering rural areas of Paarl, and 2 crèches in Stellenbosch), Paarl Municipal Council (2 clinics), and in the private sector 2 clinics and 2 crèches.

The clients at these 24 locations lived in informal settlements, in low-, middle- and high-income residential areas, and on farms as employees.

\section{Sample}

\section{Nurses}

A registered nurse was always in charge of a clinic or crèche. Staff nurses, enrolled nurses and other categories of health workers supported her, depending on the size of clinic or crèche.

One hundred and fourteen (114) nurses completed Questionnaire 1. Nurses who used the calculator answered Questionnaires 2 and 3. Questionnaire 2 was completed by 82 respondents, i.e. the 75 nurses who had agreed to use the calculator and a further 7 who had used it on their own initiative. Seventy-five (75) respondents completed questionnaire 3.

\section{Clients}

A nurse of a clinic or a researcher explained the research project to a client with a child attending a clinic or a crèche on a 'first come first served basis', and invited the client to participate in the study on a voluntary basis. Clients who thus consented with children falling into three age groups - less than 6 months, 6 months and older but less than 18 months, and 18 months to 6 years - received books (Table 1). A total of 581 books were distributed. The majority of the infants were in the birth-to-6-month age group as this was the group frequently visiting the clinics. When this category had received 243 books $(41.8 \%$ ), no more were issued to this age group. Literacy was not a criterion for selection and clients were urged to read or have their book read to them.

\section{Results \\ Nurses' responses to questionnaire 1}

Most (81.6\%) preferred the RTH book to the Road-to-Health card. It was sturdy $(95.6 \%)$, had a satisfactory layout $(87.5 \%)$, and provided useful information for health personnel (71.9\%). Nurses $(100 \%)$ found that the education material and information was helpful when advising clients on the health of or diseases affecting children.

Most nurses approved of the immunisation schedule $(97.4 \%)$, breastfeeding (95.6\%), and sections on bottlefeeding $(93.1 \%)$, weaning $(94,6 \%)$, diets (93.9\%), common ailments $(90.4 \%)$ and major problems such as diarrhoea (96.5\%). They considered clients satisfied with the book $(79.8 \%)$ and all $(100 \%)$ found the sections on breast-feeding, weaning, diarrhoea and infectious diseases very instructive. Nurses' favourable assessments of the other sections were health information (95.6\%), immunisations (94.7\%), weight charts (89.5\%), notes for staff $(91.3 \%)$ and for mothers (93.9\%), bottle-feeding ( $99.1 \%$ ), diets $(97.4 \%)$ and common ailments (97.4\%). They considered the growth charts for each age category to be more practical than the single chart on the Road-to-Health card (75.6\%) and found 
the accompanying pages useful for written measurements $(81.7 \%)$.

The horizontal centile growth chart made centiles easier to understand $(78 \%)$ and alerted one earlier to a fall in weight centile than did the Road-to-Health chart (72\%). When asked whether it was easier to use than the Road-to-Health chart, 54.9 percent replied yes while 41 percent said no. There was more certainty about their understanding of the horizontal chart: 64.4 percent could interpret it more easily than the Road-to-Health chart while 29.3 percent could not.

The growth pattern of normal, overweight and malnourished infants was correctly identified by 93 percent on the birth-to-six-month weight-for-age chart and by 85 percent on the horizontal centile growth chart. Excessive weight gain on the latter was perceived to be normal by 11 percent. This misinterpretation would need education of nurses and clients.

A large number of nurses considered the use of the electronic calculator to be timeconsuming $(70.7 \%)$. Its advantages were that display of the exact age (81.3\%) and growth centile ( $97.3 \%$ ) were quick. A fall in weight below the $3^{\text {rd }}$ centile resulted in an automatic calculation of the Z-score and this made plotting more accurate $(80 \%)$. The calculator had other uses such as determining the fluid requirement for various ages $(69.3 \%)$.

\section{Clients' responses to questionnaire 4}

The majority ( $96 \%$ ) of clients preferred the RTH book to the Road-to-Heath card and all considered it sturdy. Ninety-four percent had read it fully or had it read to them. Only 55.8 percent stated that they had received an explanation about all sections of the book from clinic staff. They appreciated its size $(90 \%)$ and the space provided for notes (93\%) and felt free to record information themselves $(88.6 \%)$. The milestones chart was particularly helpful $(90.3 \%)$ especially its illustrations $(76 \%)$ and most clients had used the charts to assess their infant's milestones $(71.5 \%)$. The immunisation section had been read by 93.4 percent and it had clarified the reasons for immunisation (88.4\%). Eighty percent $(80 \%)$ had received an explanation about immunisation from clinic staff.

The horizontal centile growth chart of the
RTH book posed difficulties and only 44.9 percent understood it better than the growth chart on the Road-to-Health card. The growth pattern of a normal, of a malnourished, and of an overweight infant was correctly identified by 75 percent of the clients on the birth-to-sixmonth weight-for-age chart and by 74 percent on the horizontal centile chart. Some clients $(15 \%)$, like 11 percent of nurses, considered excessive weight gain on this chart to be normal.

Most clients said that they had benefited from advice on minor ailments: blocked nose $(94 \%)$, sleeping position $(94 \%)$, sticky eyes (94\%), thrush (95\%), worms $(98.2 \%)$, rashes $(98.2 \%)$ and cradle cap (98.2\%). Major problems such as tuberculosis $(98.7 \%)$, burns $(97.3 \%)$, AIDS (94.6\%), diarrhoea, its treatment, and the recipe for rehydration $(96.4 \%)$ showed a similar pattern. Breast-feeding and its associated problems were well received and $85.5 \%$ of clients had been helped by the advice on how to deal with the crying baby, an inadequate breast milk supply, sore nipples, painful lumps in the breasts, over-distended breasts, and normal stools. Advice on bottle-feeding was appreciated by the majority (technique $84.9 \%$, hygiene $90.6 \%$ ), as were diets for weaning and for infants and children (93\%).

Infectious disease information had helped 93.7 percent and the majority $(95.5 \%)$ felt that the book contributed to the health of their child.

There was no noticeable difference in responses from council and private clinics where the 114 nurses, 9 from private clinics and 105 from council clinics, and the 466 clients, 55 from private clinics and 411 from council clinics, completed questionnaires.

\section{Use of the Book}

Four hundred and fifty-three (453) books were available for review. One hundred and ninety (190) of the infants were less than 5.9 months old at the time of distribution of the RTH book, and there were 126 and 137 from 6 months to 17.9 months, and 18 months to 6 years old, respectively. Most sections of the book were used (Tables II and III) with all but one of the 453 books containing the child's first name, surname and date of birth. Four hundred and seventy-seven (477) developmental assessments were recorded in 227 of the 453 books.
Assessments in 82 in the neonatal period, 101 at 6 weeks, 134 at 3 months and 160 at 6 months of age respectively were completed.

\section{Discussion}

Effective communication between levels of care is important. Patient-held or parent-held shared care records or personal child health records were introduced and evaluated in many countries between 1984 and 2000 (see references). They were found to be helpful when used by parents and professional staff. Furthermore, the concept of shared health care between primary, secondary, and tertiary care services in the United Kingdom has been accepted.

Shared care records have been found to be useful when introduced at a paediatric haematology/oncology centre (Hooker \& Williams, 1996, pp. 738-741). A parentheld child health record was introduced in the armed forces of the United Kingdom (Miller, 1990,p 1046). This card provides families who have to move home frequently with up-to-date child health information such as immunisation procedures and developmental charts.

This study and its findings constitute a review by nurses and clients of a RTH book which evolved out of a draft RTH book. The format and contents of the latter were produced by an earlier and different group of clinic staff and clients in association with the authors.

Results of this study indicate that nurses and clients found the format and contents of the RTH book useful. Responses given in Questionnaire 1 indicated that nurses (81.6\%) and clients (96\%) from a crosssection of the clinic services and of the population in the Cape Peninsula preferred a personal retained document in book form for infants and children.

The RTH book was well understood and utilised by the majority of nurses and by both literate and illiterate clients. The latter asked for help from their literate children and friends and in this way expanded child health knowledge in the community. The RTH book served as a tool for education and communication between clients and various health agencies including child health clinics and crèches, hospitals, and medical practitioners in the public health and private health sectors. In instances where the client had in the interim, 
between visits to the clinic, attended hospitals or medical practitioners, notes made in the RTH book prevented duplication of treatment and medication. The researchers observed that educational pamphlets were often discarded within a clinic and its surroundings. Whether educational pamphlets serve their purpose at home is unknown. The RTH book probably has the potential of being a more effective source of information than pamphlets. Similar sentiments were expressed by O'Flaherty, Jandra, Llewellyn \& Wall, 1987, p.1152-1155, in their evaluation of personal health records in Australia.

Nurses and clients benefited from and appreciated the information on feeding, minor ailments, potentially harmful symptoms and signs which reinforced advice provided at clinics. Usage was also reflected in notes made by clinic staff and most had filled in details of immunisation and other health matters. $31.8 \%$ of clients had also used the opportunity to make notes.

The RTH book has proved to be a useful documentary health record liked by nurses and clients. The information encourages parents and caregivers to participate in primary health care and encourages them to share in the management of their child's health. It also offers them the opportunity to know when to be concerned about their infant's growth, health, and development. In this respect the cost of issuing a RTH book as opposed to the Road-to-Health card needs to be addressed. The savings on health literature and pamphlets issued by clinics should be included in the calculations of the cost. Findings in the present study are in many aspects similar to experience in the United Kingdom (Lakhani, Avery, Gordon \& Tait, 1984, p. 1076-1081) and Australia (O'Flaherty, Janra, Llewellyn \& Wall, 1987, p.11521155; Jeffs, Nossar, Bailey, Smith \& Chey, 1994, pp. 248-252; Volkmer, Goldstone \& Ninnes, 1993, p.1). In the Volkmer, Goldstone \& Ninnes study (1993, pp. 150153 ), over $90 \%$ of parents retained their books and used them frequently for visits to general practitioners, clinics and hospitals

Growth monitoring without education is considered to be futile (Griffiths 1988, pp. S59-S66). Growth charts that are to be included in any health document must be easily understood and plotting must be simple, preferably with separate charts for male and female so that the "at risk" child is identified early. The unisex growth chart of the Road-to-Health card and horizontal centile chart were used in this survey. The latter was perceived to be more accurate than the chart of the Road-to-Health card, but an unacceptably high percentage of nurses (35.6\%) and clients $(55.1 \%)$ did not understand the horizontal centile chart. The latter is in agreement with the finding of Ruel, Pelletier, Habicht, Mason, Chobokoane \& Maruping (1991,pp. 610615) in Lesotho. The horizontal centile chart therefore cannot be recommended for inclusion in the RTH book. Likewise, nurses found that the electronic calculator offered accurate calculation of age $(81.3 \%$ ), centile ( $97.3 \%$ ) and Z-score $(80 \%)$, but they perceived it to be timeconsuming $(70.7 \%)$, which makes it unlikely to be used for monitoring until personal computers and appropriate software programmes are installed in clinics and crèches. Inclusion of both the unisex growth charts and horizontal centile growth charts in such software programmes would enhance monitoring of a child's health by health personnel. Deviation from centile lines on a child's growth chart would be more accurate and would lead to earlier intervention by health personnel. Compilation of statistics such as over- or under-nutrition and disease would be less labourintensive than current manual methods, as both clinic staff and health administrators would benefit.

It is thus recommended that the RTH book should be introduced in the Western Cape Province to replace the Road-toHealth card currently in use. Appropriate changes and improvements in health monitoring which may subsequently have occurred in fields such as immunisation schedules and management of Aids may be indicated. The authors claim no experience of the requirements of a RTH book for rural areas such as the Eastern Cape Province. However, studies as those by Kuhn and Zwarenstein, (1990, pp. 685-692) in the Ciskei have demonstrated the value of a village health worker-retained record for the first year of life in ongoing health care evaluation. Introduction of the RTH book in other areas and regions of South Africa may require modification to cover illnesses not common in the Western Cape, such as malaria.

Factors such as culture, attitude of clinic staff and community, and educational levels and literacy of mothers and siblings may also have an influence on content and usage by health personnel and clients.

Nurses and clients find the current Roadto-Health card unsatisfactory, as it does not fulfil their requirements. Information desired by both cannot be contained on the present Road-to-Health card and should be presented in a book. The latter should become an important mother- or caregiver-held child health document.

\section{Limitations}

In this study, the use of the RTH book compared to the use of the Road-ToHealth card was not carried out, as there were so many additional pages to record information in the RTH book.

Cost-effectiveness of the RTH book in terms of child health and maternal health education compared to the currently used Road-to-Health card, including the cost of additional printed educational material, will have to be assessed by health administrators. Likewise, the cost of installing the calculator in all clinics makes it unlikely to be used for monitoring in the immediate future.

\section{Acknowledgements}

We are indebted to and thank all of those who contributed to the study. The success of the pilot and current studies was dependent on the input, enthusiasm, and sustained co-operation of clinic staff in both the public and private sectors. Advice and permission were sought from Dr ME Popkiss (Medical Officer of Health of the Cape Town City Council) and Dr S A Fischer (Western Cape Regional Services Council). Dr G H Visser (Councils Maternity and Child Health Services), Mrs V Dekenah (Nursing Services Manager of the City Health Department), Mrs J Honeyman (Chief Nursing Services Management) and Dr G Lawrence, responsible for Child Health Programmes, were also contacted. Individuals in the fields of medicine, nursing, nutrition and childhood development contributed their expertise to relevant sections of the RTH book. Dr L Henley assisted with the formatting and wording of the questionnaires. The late Prof. F P S le Roux was responsible for the Afrikaans translation and Sister Pumla Mkaza advised on the Xhosa translation of the RTH book. Funding 
from the Rita and Bernard Fellowship of the Department of Paediatrics and Child Health enabled us to carry out the research project. Ms Adele Pearce assisted with the preparation of the manuscript. Mr Clyde Broster proofread the paper.

\section{REFERENCES}

\section{BRITISH PAEDIATRIC ASSOCIATION}

Report of a joint working party on professional and parent records used in child health surveillance.' London: British Paediatric Association, 1990.

DAVIAUD, E; CEBEKHULU, Q \& MONIEZ, V 1996: 'Patient-retained records - experience at the Alexandra Health Centre.' South African Medical Journal. vol.86, pp. 986-987.

GRIFFITHS，M 1988: 'Growth monitoring - Making it a tool for education.' Indian Journal of Pediatrics (Suppl), vol. 55,pp. S59-S66.

HARRISON, D; HEESE, H DEV; HARKER, H \& MANN, MD 1998: 'An assessment of the "Road-to-Health" card based on perceptions of clinic staff and mothers.' South African Medical Journal. vol. 88, pp. 1424-1428.

HOOKER, L \& WILLIAMS, J 1996: 'Parent-held shared care records: bridging the communication gap'. British Journal of Nursing. vol. 5, pp. 738-741.

JEFFS, D; NOSSAR, V; BAILEY, F; SMITH, W \& CHEY, T 1994: 'Retention and use of personal health records: a population-based study.' Journal of Pediatrics and Child Health. vol. 30, pp. 248-252.

KUHN, L \& ZWARENSTEIN M 1990: 'Evaluation of a village health worker programme: The use of the village health worker retained records.' International Journal of Epidemiology. vol. 19, pp. 685692.

LAKHANI, AD; AVERY,A; GORDON, A \& TAIT, N 1984: 'Evaluation of a home based health record booklet.' Archives of Disease in Childhood. vol. 59, pp.10761081.

MACFARLANE, A 1992: 'Personal child health records held by parents.' Archives of Disease in Childhood, vol. 67, pp. 571572.
MILLER, SA ST J: 1990, 'A trial of parent-held child health records in the armed forces'. British Medical Journal. vol. 300 , p. 1046.

O'FLAHERTY, S; JANDERA, E; LLEWELLYN, J \& WALL, M 1987:

'Personal health records: an evaluation'. Archives of Disease in Childhood. vol. 62, pp. 1152-1155.

RUFL,MT,PEL LETIER,DL; HABICHT, J; MASON, JB; CHOBOKOANE, CS \& MARUPING, AP 1991: 'Comparison of two growth charts in Lesotho: health workers' ability to understand and use them for action.' American Journal of Public Health. vol. 81, pp. 610-615.

SAFFIN, K \& MACFARLANE, A 1991: 'How well are parent-held records kept and completed?' British Journal of General Practice. vol. 41, pp. 249-251.

SORVA, R; PERHEENTUPA, J \& TOLPPANEN, E 1994: 'A novel format for a growth chart.' Acta Paediatrica Scandinavica. vol. 73, pp. 527-529.

VOLKMER, RE; GOLDSTONE, MA \& NINNES, C $P$ 1993: 'Parental perception of the use of and usefulness of a parentheld health record.' Journal of Paediatrics and Child Health. vol. 29, pp.150-153. 